DOI: $10.5455 / 2320-1770 . \mathrm{ijrcog} 20141223$

Research Article

\title{
Twin births: an overview
}

\section{Sanjivani Anil Wanjari*}

Department of Obstetrics \& Gynecology, Lata Mangeshkar Hospital Extended Teaching Programme at Daga Hospital, Nagpur, Maharashtra, India

Received: 21 September 2014

Accepted: 10 October 2014

\section{*Correspondence:}

Dr. Sanjivani Anil Wanjari,

E-mail: sanjivaniwanjari@yahoo.com

Copyright: ( ) the author(s), publisher and licensee Medip Academy. This is an open-access article distributed under the terms of the Creative Commons Attribution Non-Commercial License, which permits unrestricted non-commercial use, distribution, and reproduction in any medium, provided the original work is properly cited.

\section{ABSTRACT}

Background: The aim of this study was to investigate the maternal, foetal and obstetric parameters surrounding twin pregnancies. An attempt was made to find out the perinatal mortality and morbidity rates of twin births and to determine the underlying factors responsible for the increase in these rates.

Methods: A one year observational study was done at Daga hospital Nagpur, which is a referral maternity hospital receiving a large number of antenatal patients daily. Perinatal mortality and morbidity rates, gestational age at delivery, birth weight, route of delivery, and caesarean section rates were analysed.

Results: The commonest presentation in our study vertex/vertex presentation (62\%). A large percentage of twins in our study had a normal delivery. $37 \%$ women had caesarean section. In our study nearly $17 \%$ of the neonates had birth weights $<1.5 \mathrm{~kg}$. In $51 \%$ women the first baby had more birth weight than the second twin. Among the 95 twin births (190 twins) studied, we had one discordant twins and one conjoined twins.

Conclusions: Twin pregnancies are high risk pregnancies with more obstetrical complications compared to singleton pregnancies. Twin pregnancies have higher perinatal mortality and morbidity rates especially before 34 weeks of gestation. Hence deliveries should be performed in referral centres with competent NICUs.

Keywords: Twin births, Prematurity, Low birth-weight, Perinatal morbidity \& mortality

\section{INTRODUCTION}

Twinning has fascinated human beings over the centuries. The rate of twin pregnancies is on the rise all over the world. The twin birth rate in the United States rose $76 \%$ from 1980 through 2009, from 18.9 to 33.3 per 1000 births. ${ }^{1}$ Since monozygotic (MZ) twinning is considered constant at around 3-4/1000, this increase is mainly due to frequent dizygotic (DZ) twinning. ${ }^{2}$ This increase has been largely attributed to the introduction of assisted reproduction techniques, increased use of ovulationinducing drugs, and delayed childbearing ${ }^{3}$ and due to ethnic differences and maternal age. New born twins are considered a high risk group as they are much more likely to suffer from low birth weight, prematurity and distress during labour and delivery. ${ }^{4,5}$ The aim of this study was to investigate the maternal, foetal and obstetric parameters surrounding twin pregnancies and to find out the perinatal mortality and morbidity in twin births.

\section{METHODS}

An observational one year study of twin pregnancies was done between $1^{\text {st }}$ July 2013 till $30^{\text {th }}$ June 2014 at Daga hospital Nagpur which is a large maternity hospital receiving complicated referrals from the periphery. During the one year study period, there were 95 twin births (190 twins). Women with pregnancies less than 28 weeks of gestation were excluded from the study. A thorough evaluation of twin pregnancies was done regarding presentation, gestational age at delivery, mode 
of delivery, birth weights, and perinatal morbidity \& mortality.

\section{RESULTS}

\section{High maternal parameters}

The women in our study were mainly from the low socioeconomic strata of society. Most of the mothers were in the age group of 20-30 years. There was only one teenage twin pregnancy in our study and 4 women were over 30 years of age.

\section{Obstetric parameters}

Presentation - The commonest presentation in our study vertex/vertex presentation (62\%). Vertex/breech was the second commonest presentation (17\%), followed by breech/vertex presentation (15\%). Breech/breech presentation accounted for (3\%), transverse/vertex (1\%), vertex/transverse $(1 \%)$. There was case of conjoined twins in our study (1\%) (Table 1).

Table 1: Obstetric parameters: presentation.

\begin{tabular}{|lll|}
\hline Presentation & Number & Percentage \\
\hline Vertex/vertex & 59 & 62 \\
\hline Vertex/breech & 16 & 17 \\
\hline Breech/vertex & 14 & 15 \\
\hline Breech/breech & 3 & 3 \\
\hline Transverse/vertex & 1 & 1 \\
\hline Vertex/transverse & 1 & 1 \\
\hline Conjoined twins & 1 & 1 \\
\hline
\end{tabular}

Mode of delivery - A large percentage of twins in our study had a normal delivery (61\%). 37\% women had caesarean section and in two of the women the first baby had a normal vaginal delivery but had a caesarean section for delivery of the second twin (2\%) (Table 2). Important indications for caesarean section were premature rupture of membranes, compound presentation \& cord prolapse, hypertensive disorders of pregnancy, obstructed labour and prior scar.

Table 2: Obstetric parameters: mode of delivery.

\begin{tabular}{|lll|}
\hline Mode of delivery & Number & Percentage \\
\hline Normal & 58 & 61 \\
\hline Caesarean section & 35 & 37 \\
\hline First normal, second caesarean & 2 & 2 \\
\hline
\end{tabular}

\section{Foetal parameters}

Birth weight - The birth weight of $49 \%$ of first twins was in the range of 2 to $2.5 \mathrm{Kg}$ and nearly $40 \%$ of second twins had birth weights between 2 to $2.5 \mathrm{~kg}$. In $51 \%$ women the first baby had more birth weight than the second twin. In $36 \%$ the second twin had a birth weight greater than that of the first twin. In $13 \%$ there was no difference in weight between the first and second twins (Table 3). There was one patient with conjoined twins (thorcoapagus) where in the combined weight was 3.2 $\mathrm{Kg}$. This woman was delivered by caesarean section for obstructed labour. The baby was stillborn.

Table 3: Foetal parameters: birth weight.

\begin{tabular}{|lllll|}
\hline \multirow{2}{*}{ Birth weight } & \multicolumn{2}{l}{ First twin } & \multicolumn{2}{l|}{ Second twin } \\
\cline { 2 - 5 } & No. & \% & No. & \% \\
\hline $1-1.49 \mathrm{~kg}$ & 2 & 2 & 3 & 3 \\
\hline $1.5-1.99 \mathrm{~kg}$ & 30 & 32 & 36 & 38 \\
\hline $2-2.5 \mathrm{~kg}$ & 47 & 49 & 38 & 40 \\
\hline$>2.5 \mathrm{~kg}$ & 3 & 3 & 4 & 4 \\
\hline
\end{tabular}

There was one patient with discordant twins which had a weight difference of $16 \%$. The first twin which had a birth weight of $2.2 \mathrm{Kg}$ survived and was discharged in good condition. The second twin which was just $550 \mathrm{gm}$ in weight was a macerated stillbirth. The second twin had died at 28-30 weeks of gestation and the patient had a normal delivery at term.

\section{Perinatal morbidity \& mortality}

Nearly $50 \%$ of the twins needed admission to NICU for various indications like prematurity, birth asphyxia, low birth weight, meconium staining of liquor \& delivery by caesarean section. Respiratory morbidity was observed despite antenatal corticosteroid exposure. $19 \%$ patients had a preterm delivery before 34 weeks of gestation. There were 34 perinatal deaths in our study (18\%).

\section{DISCUSSION}

It is a well-known fact that the presentation in twin pregnancy affects the mode of delivery and the perinatal outcome. In our study the commonest presentation was vertex/vertex (62\%). Most common mode of delivery was normal vaginal delivery. However $37 \%$ of women had caesarean section. Important indications for caesarean section were premature rupture of membranes, compound presentation \& cord prolapse, hypertensive disorders of pregnancy, obstructed labour and prior scar.

More than a fourth of the very low birth weight neonates $(<1.5 \mathrm{~kg})$ born in the United States are due to multiple gestations. ${ }^{6}$ In our study nearly $17 \%$ of the neonates had birth weights $<1.5 \mathrm{~kg}$. Multiple pregnancies are much less likely to carry to full term than single births, with twin pregnancies lasting only 37 weeks (3 weeks less than full term) on average. ${ }^{7}$ Delivery before term is the major reason for increased neonatal morbidity and mortality in twins. $^{8,9} 19 \%$ patients had a preterm delivery before 34 weeks of gestation.

For the last 50 years, the term "perinatal mortality" has been used to include deaths that might somehow be attributed to obstetric events, such as stillbirths and 
neonatal deaths in the first week of life. Perinatal mortality is an important indicator of maternal care and of maternal health and nutrition; it also reflects the quality of obstetric and paediatric care available. Compared with singletons, twins experience perinatal mortality rates 4 to 10 times higher. ${ }^{10}$ In our study among the 95 twin births (190 twins), there were 8 (4\%) stillbirths and $26(14 \%)$ early neonatal deaths i.e. 34 (18\%) perinatal deaths. According to Gezer et al., ${ }^{11}$ the principal causes of perinatal mortality were prematurity, foetal demise and congenital abnormalities. The main cause of morbidity was Respiratory Distress Syndrome (RDS). In neonatal period $28 \%$ of new-borns needed neonatal Intensive Care Unit (NICU). In our study the main causes of foetal morbidity were prematurity and respiratory distress. Almost $50 \%$ of the babies required admission to NICU. Perinatal mortality was mainly due to prematurity, respiratory distress syndrome and septicaemia. There was one discordant twins in our study. The larger twin with birth weight of $2.2 \mathrm{~kg}$ survived and was discharged in good condition while the other twin of 550 grams was macerated IUD. Although there is lack of consensus on the precise threshold of discordance, according to ACOG discordance is defined as difference in actual weight of twins between $15-25 \% .^{12}$

Walker et al. ${ }^{13}$ found that in multiple gestations the risks of preeclampsia, post-partum bleeding and maternal death increased twofold or more. There was no maternal death in our study. However maternal morbidity was due to hypertension, sepsis secondary to premature rupture of membranes, anaemia and post-partum bleeding.

\section{CONCLUSION}

Twin pregnancies are high risk pregnancies with more obstetrical complications compared to singleton pregnancies. Therefore they should be monitored more intensely and appropriate precautions should be taken against obstetrical complications. Twin pregnancies have higher perinatal mortality and morbidity rates especially before 34 weeks of gestation. Hence deliveries should be performed in referral centres with competent NICUs.

Funding: No funding sources Conflict of interest: None declared

Ethical approval: The study was approved by the institutional ethics committee

\section{REFERENCES}

1. Martin, Joyce A, Hamilton, Brady E, Osterman, Michelle JK. Three decades of twin births in the
United States, 1980-2009. In: Martin, Joyce A, Hamilton, Brady E, Osterman, Michelle JK, eds. NCHS Data Brief, No. 80. Hyattsville, MD: National Centre for Health Statistics; 2012: 1-8.

2. Pison G. Twins in sub-Saharan Africa: Frequency, social status and mortality. In: van de Walle E, Pison G, Sala-Diakanda M, eds. Mortality and Society in Africa. 1st ed. Oxford: Clarendon Press; 1992.

3. MMWR. Contribution of assisted reproductive technology and ovulation-inducing drugs to triplet and higher-order multiple births: United States, 1980-1997. MMWR Morb Mortal Wkly Rep. 2000;49:535-8.

4. McDermott JM, Steketee R, Wirima J. Mortality associated with multiple gestations in Malawi. Int $\mathbf{J}$ Epidemiol. 1995;24(2):413-9.

5. Hall JG. Twinning. Lancet. 2003;362(9385):735-43.

6. Martin JA, Hamilton BE, Sutton PD, Ventura SJ, Menacker F, Kirmeyer S. Births. Final data for 2004. Natl Vital Stat Rep. 2006 Sep;55(1):1-101.

7. Elliott JP. Preterm labour in twins and high-order multiples. Clin Perinatol. 2008 Dec;34(4):599-609.

8. Gardner MO, Goldenberg RL, Cliver SP, Tucker JM, Nelson KG, Copper RL. The origin and outcome of preterm twin pregnancies. Obstet Gynaecol. 1995;85:553-7.

9. Joseph KS, Allen AC, Dodds L Vincer MJ, Armson BA. Causes and consequences of recent increases in preterm birth among twins. Obstet Gynaecol. 2001;98:57-64.

10. Kiely JL. The epidemiology of perinatal mortality in multiple births. Bull N Y Acad Med. 1990;66:61837.

11. Altay Gezer, Muhabbet Rashidova, Onur Güralp, Fahri Öçer. Perinatal mortality and morbidity in twin pregnancies: the relation between chorionicity and gestational age at birth. Gynaecol Obstet. 2012 Feb;285(2):353-60.

12. American College of Obstetricians \& Gynaecologists Committee on Practice Bulletins-Obstetrics; Society for Maternal-Fetal Medicine; ACOG Joint Editorial Committee. ACOG Practice Bulletin \#56: Multiple gestations: complicated twin, triplet \& higher order multifetal pregnancy. Obstet Gynaecol. 2004 Oct;104(4):869-83.

13. Walker MC, Murphy KE, Pan S, Yang Q, Wen SW. Adverse maternal outcomes in multifetal pregnancies. BJOG. 2004;111:1294-6.

DOI: $10.5455 / 2320-1770 . i j \operatorname{cog} 20141223$

Cite this article as: Wanjari SA. Twin births: an overview. Int J Reprod Contracept Obstet Gynecol 2014;3:995-7. 